\title{
Análise estatística multivariada aplicada em amostras de água subterrânea da região do Cariri, sul do Estado do Ceará
}

\author{
Maria da Conceição Rabelo GOMES \& Luiz Alberto Ribeiro MENDONÇA
}

Universidade Federal do Cariri. Av. Tenente Raimundo Rocha, S/N, Cidade Universitária, CEP 63048-080, Juazeiro do Norte, CE, Brasil (conceicaorabelo@yahoo.com.br, larm@ufc.br).

Recebido em 11/2016. Aceito para publicação em 11/2017.

Versão online publicada em 16/3/2018 (www.pesquisasemgeociencias.ufrgs.br)

\begin{abstract}
Resumo - Na área constituída por parte dos municípios de Barbalha, Crato e Juazeiro do Norte, sul do Estado do Ceará, os recursos hídricos subterrâneos são a única fonte de abastecimento público e privado e a superexplotação já é evidenciada na intermitência da antiga rede de drenagem perene, hoje perenizada por lançamentos de esgotos. A evolução química das águas subterrâneas foi estudada identificando similaridades entre variáveis físico-químicas, discriminando as mais significativas, através da metodologia da análise estatística multivariada para explicar possíveis processos responsáveis pela qualidade das águas na área. A análise fatorial identificou três componentes responsáveis por aproximadamente $85 \%$ da variância total; o primeiro como indicador da dissolução dos minerais presentes na Formação Rio da Batateira e Formação Santana; o segundo e o terceiro fatores como indicadores de uma possível mistura entre as águas naturais do aquífero com águas poluídas. A análise de agrupamento multivariada por componente, apresentou quatro grupos no fator 1 e dois grupos nos fatores 2 e 3 , identificados por amostras com diferentes faixas de concentrações. Na análise discriminante, as variáveis mais significativas nos processos responsáveis pela evolução hidroquímica da área foram o $\mathrm{Mg}^{2+} \mathrm{e} \mathrm{K}$, podendo estar relacionados a processos de troca iônica e intemperismo de feldspatos.
\end{abstract}

Palavras-chave: Hidroquímica, análise de agrupamento, análise fatorial, análise discriminante.

\begin{abstract}
Multivariate STATISTICAL ANALYSiS APPLIED IN SAMPLES OF GROUNDWATER IN THE REGION OF CARIRI, SOUTH OF THE STATE OF CEARÁ. In the area constituted by the municipalities of Barbalha, Crato and Juazeiro do Norte, south of Ceará State, groundwater resources are the only source of public and private water supply, and overexploitation is already evident in the intermittency of the old perennial drainage network, now perpetuated by sewage launches. The chemical evolution of groundwater was studied by identifying of similarities between physicochemical variables, discriminating the most significant ones, through the methodology of multivariate statistical analysis to explain possible processes responsible for water quality in the area. The factorial analysis identified three components responsible for approximately $85 \%$ of the total variance; the first one as an indicator of the dissolution of the minerals present in the Rio da Batateira and Santana formations; the second and third factors as indicators of a possible mixture between the natural waters of the aquifer with polluted waters. Multivariate cluster analysis by component showed four groups in factor 1 and two groups in factors 2 and 3, identified by samples with different concentration ranges. In the discriminant analysis, the most significant variables in the processes responsible for the hydrochemical evolution of the area were $\mathrm{Mg}^{2+}$ and $\mathrm{K}^{+}$, being able to be related to ion exchange processes and weathering of feldspars.

Keywords. Hydrochemistry, cluster analysis, factor analysis, discriminant analysis.
\end{abstract}

\section{Introdução}

A análise estatística multivariada é uma ferramenta importante na manipulação de dados com muitas variáveis, facilitando a interpretação das informações devido a uma redução no número de variáveis, fazendo com que o fenômeno sob estudo seja representado da maneira mais simples possível, sem sacrificar informações valiosas (Ferreira,
1996).

Em geociências, as técnicas de estatística multivariada mais utilizadas são as análises de agrupamento hierárquico, fatorial e discriminante (Landim, 2011). Na geoquímica de águas subterrâneas, a análise de agrupamento hierárquico é utilizada na identificação de similaridades entre variáveis (Fernandes et al., 2010; Salgado et al., 2011) e a análise fatorial, no estudo da evolução 
química, identificando variáveis responsáveis pela mudança qualitativa das águas (Wang \& Luo, 2001, Cloutier et al., 2008; Andrade et al., 2010). A combinação das análises de agrupamento hierárquico e fatorial pode ser utilizada na avaliação da origem geoquímica de águas subterrâneas, identificando variáveis responsáveis por alterações hidroquímicas (Brito et al., 2006; Machado et al., 2008; Arslan, 2013). Neste contexto, a inclusão da análise discriminante permitirá também conhecer as variáveis mais significativas nos processos responsáveis pela evolução hidroquímica (Lambrakis et al., 2004). Os resultados destas análises são importantes como suporte ao monitoramento e à gestão da qualidade de águas subterrâneas, principalmente em regiões semiáridas, que são de alta vulnerabilidade socioambiental.

Este trabalho tem como estudo de caso a porção do aquífero arenítico Rio da Batateira, localizado no setor leste da Bacia Sedimentar do Araripe. Nesta área, os recursos hídricos subterrâneos são a única fonte de abastecimento público e privado e a superexplotação já é evidenciada na intermitência da antiga rede de drenagem perene, hoje perenizada por lançamentos de esgotos.

Neste estudo foram utilizadas as análises fatorial, agrupamento hierárquico e discriminante, objetivando entender a evolução química das águas subterrâneas, identificando similaridades entre variáveis físico-químicas e discriminando os grupos, dados com uma variável categórica dependente e variáveis de escala intervalar independentes.

\section{2 Área, materiais e métodos}

\subsection{Caracterização da área}

A área de estudo envolve parte dos municípios de Crato, Juazeiro do Norte e Barbalha (CRAJUBAR) (9185000 - $9215000 \mathrm{~N}$ e $450000-475000$ S, Zona 24S, SAD-69 datum) (Fig. 1), no vale do Cariri cearense, caracterizada por um clima tropical quente semiárido, com temperatura média de 24 a $26{ }^{\circ} \mathrm{C}$ e precipitação pluvial média anual de 925 $\mathrm{mm}$, com período chuvoso de janeiro a maio (IPECE, 2015).

Nesta área aflora predominantemente a Formação Rio da Batateira (Fig. 1), caracterizada por arenitos argilosos médios a finos, com espessura média de $200 \mathrm{~m}$, na base por siltitos argilosos e folhelhos betuminosos e fossilíferos (Ponte \& Appi, 1990 ), constituindo o aquífero explotado mais importante.
Esta unidade geológica corresponde a base do Grupo Araripe (Mesozoica), que é sotoposta a outras formações na Chapada do Araripe: Santana, que é composta predominantemente por calcita, gipsita e folhelhos; Arajara, por siltitos, argilitos e arenitos finos argilosos; e Exú, por arenitos friáveis, argilosos, de granulometria variável, aflorante no topo da Chapada (Ponte \& Appi, 1990). As formações Arajara e Exú são caracterizadas como aquíferos e a Santana, como aquiclude.

Sotopostos à Formação Rio da Batateira encontram-se as formações Abaiara, Missão Velha, que são aquíferos, e a Brejo Santo, que é um aquiclude, pertencentes ao Grupo Vale do Cariri (Mesozoica). Na base desse pacote sedimentar, encontra-se a Formação Mauriti (Paleozoica), que é um aquífero, depositada sobre rochas do embasamento pré-cambriano.

\subsection{Materiais e métodos}

Em outubro de 2015 foram coletadas 30 amostras de águas subterrâneas em poços localizados na região de CRAJUBAR (Fig. 1), para a realização de análises físico-químicas. Os parâmetros físico-químicos analisados foram: $\mathrm{pH}$, condutividade elétrica (CE), salinidade, sólidos totais dissolvidos (STD), bicarbonato $\left(\mathrm{HCO}_{3}^{-}\right)$, cloretos $\left(\mathrm{Cl}^{-}\right)$, sulfatos $\left(\mathrm{SO}_{4}{ }^{2-}\right)$, sódio $\left(\mathrm{Na}^{+}\right)$, potássio $\left(\mathrm{K}^{+}\right)$, cálcio $\left(\mathrm{Ca}^{2+}\right)$, magnésio $\left(\mathrm{Mg}^{2+}\right)$, ferro total ( $\left.\mathrm{Fe}\right)$, alumínio $\left(\mathrm{Al}^{3+}\right)$, fluoretos ( $\left.\mathrm{F}^{-}\right)$, dureza total (DT - $\mathrm{CaCO}_{3}$ ), amônia $\left(\mathrm{N}-\mathrm{NH}_{4}^{+}\right)$, nitrito $\left(\mathrm{N}-\mathrm{NO}_{2}^{-}\right)$, nitrato $\left(\mathrm{N}-\mathrm{NO}_{3}^{-}\right)$, fosfato $\left(\mathrm{P}^{-\mathrm{PO}_{4}{ }^{3}-}\right), \mathrm{CO}_{2}$ livre, oxigênio dissolvido (OD), turbidez e cor. Os 30 poços amostrados e as 23 análises físico-químicas totalizam 690 resultados.

Inicialmente as análises físico-químicas foram submetidas ao cálculo do balanço iônico e, posteriormente, tratadas estatisticamente. Uma análise hidroquímica completa, a concentração (em meq/L) total de íons positivos (cátions) deve ser aproximadamente igual à concentração de íons negativos (ânions). Esse cálculo foi realizado mediante a utilização da equação 1 definida por Logan (1965), que define o coeficiente individual de erro das análises, admitindo-se um valor máximo de $10 \%$ para analises aproveitáveis. Este valor percentual está associado à concentração total dos cátions e dos ânions. (Eq. 1)

$$
E(\%)=\left(\sum A-\sum C / \sum A+\sum C\right) \times 100
$$

onde: $\sum \mathrm{A}=$ Somatório de ânions (meq/L); $\sum \mathrm{C}$ = Somatório de cátions (meq/L); E = Erro das análises e meq/L = Mili-equivalente por litro. 


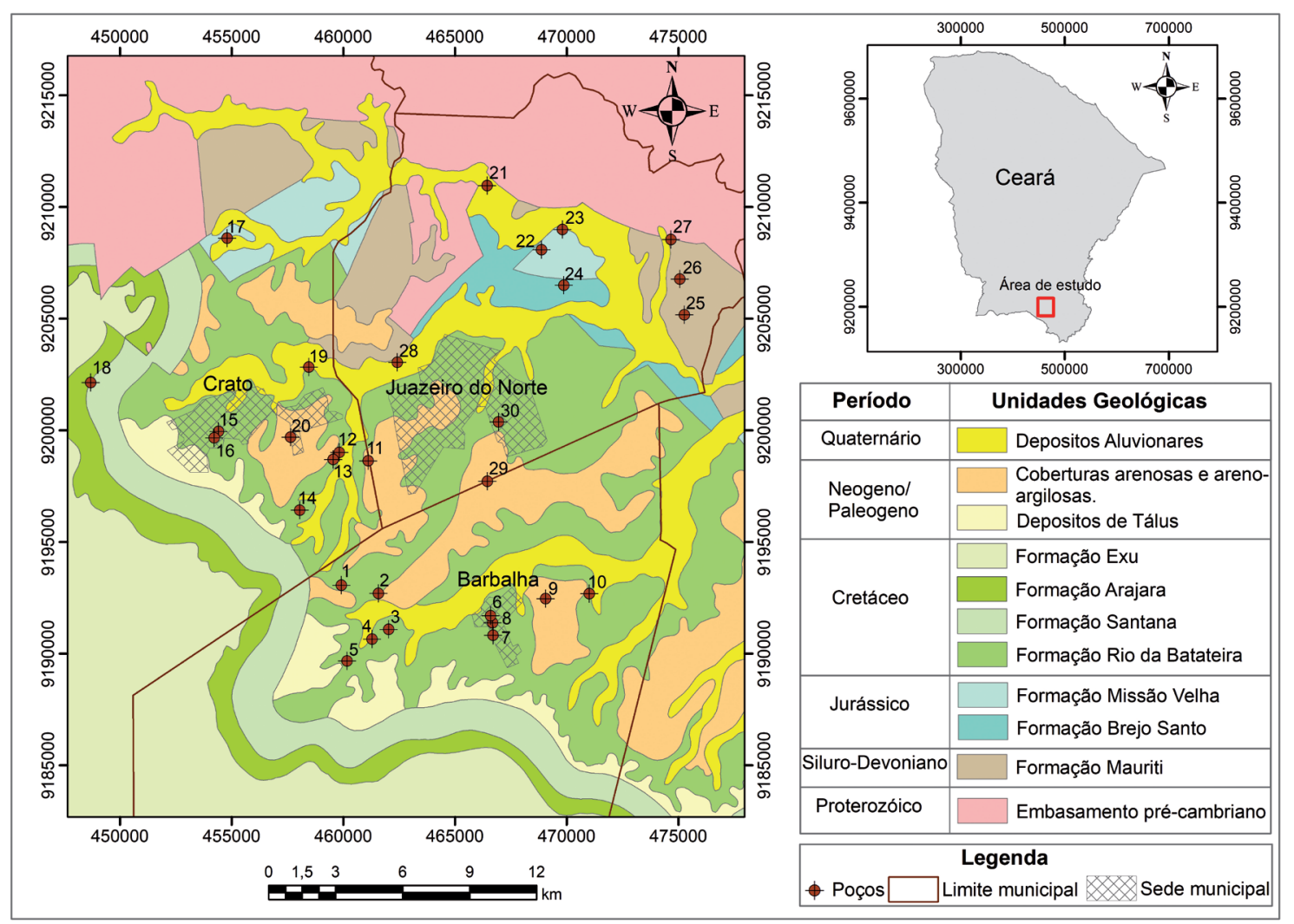

Figura 1. Localização da área de estudo, unidades geológicas aflorantes e poços amostrados (modificado de CPRM, 2007). Figure 1. Location of the study area, outcropping geological units and sampled wells (modified from CPRM, 2007).

A análise estatística foi iniciada com a avaliação do grau de associação entre as variáveis físico-químicas, através da matriz de correlação de $P e$ arson. Em seguida, foram aplicadas as técnicas de análise multivariada, que foram processadas no software SPSS Statistics, versão 17.0.

A partir da análise fatorial buscou-se identificar dimensões de variabilidade comuns (ou fatores) existentes em um conjunto de fenômenos, para desvendar estruturas existentes, mas não observáveis diretamente. Nesta análise aplicou-se o método das componentes principais, utilizando a rotação varimax normalizada. Tal abordagem trata-se de uma técnica para encontrar componentes lineares de variáveis correlacionadas por meio do cálculo dos autovalores e correspondentes autovetores de uma matriz de variâncias-covariâncias ou de uma matriz de coeficientes de correlação entre variáveis (Hoffmann, 1992; Manly, 1998; Landim, 2011; Araújo et al., 2013). Este procedimento reduziu a dimensão original das $n$ variáveis, gerando coeficientes de correlação, facilitando a interpretação do domínio de observações e identificando grupos de águas com seus principais componentes de qualidade. A verificação da adequação dos dados e a análise fatorial foram feitas a partir do índice KMO (Kaiser-Meyer-Olkin Measure of Sampling Adequacy) e do teste estatístico de esfericidade de
Bartlett, que testa a hipótese nula de que as variáveis analisadas não são correlacionadas (Hair Jr. et al., 1998; Araújo et al., 2013).

$\mathrm{Na}$ análise de agrupamento hierárquico (análise de conglomerados ou clusters analysis), as amostras foram agrupadas a partir do maior número de variáveis explicadas por um único fator da análise fatorial. Nessa técnica, utilizou-se o método Ward como critério hierárquico de agrupamento, com medida de similaridade dada pela distância euclidiana quadrada (squared euclidean distance). Esse critério hierárquico de agrupamento utiliza a soma total dos quadrados dos desvios de cada objeto em relação à média do grupo no qual o mesmo foi inserido. A escolha deste critério se fundamentou na frequente empregabilidade do mesmo em estudos de qualidade da água (Vega et al., 1998; Andrade et al., 2008; Yidana \& Banoeng-Yakubo, 2008; Palácio, 2009; Fernandes, et al., 2010; Salgado et al., 2011; Arslan, 2013). 0 agrupamento foi apresentado por meio de um dendrograma e o ponto de "corte", utilizado na definição do número de grupos, foi definido na maior variação da distância reescalonada do coeficiente de aglomeração (Ferreira, 1996). Os grupos formados pela técnica de agrupamento tiveram suas médias comparadas pelo teste $t$ de Student aos níveis de 5\% e 1\%, após execução da análise de variância. Estes testes indi- 
cam as variáveis responsáveis pela formação dos grupos na análise multivariada.

A técnica da análise discriminante foi aplicada ao conjunto de variáveis de cada grupo da análise de agrupamento hierárquico. A partir desta técnica foi possível determinar a existência de diferenças significativas entre estas variáveis, identificar as variáveis que melhor diferenciam os grupos e descrever uma ou mais funções discriminantes que representem as diferenças entre grupos.

A análise discriminante pode ser classificada em simples, quando é composta por dois grupos discriminantes e múltipla, por mais de dois. A equação 2 define uma função discriminante linear.

$$
Z=b_{1} X_{1}+b_{2} X_{2}+\ldots+b_{n} X_{n}+a
$$

em que $\mathrm{Z}$ é a variável dependente, Xn são as variáveis independentes (explicativas) e bn são os coeficientes discriminantes (correspondentes ao peso de cada variável independente na função).

Os coeficientes discriminantes são agrupados de acordo com a correlação entre as variáveis explicativas e a função discriminante. Eles podem ser utilizados na avaliação da importância relativa de cada variável independente para a função discriminante obtida.

A função discriminante foi obtida a partir de uma subamostra contendo $70 \%$ da amostra total.

A acurácia do modelo foi calculada a partir da validação cruzada (cross-validation). Nesse procedimento foram utilizadas uma validação interna (considerando os $70 \%$ da amostra total) e outra externa (considerando os 30\% restantes). Na validação interna verificou-se a eficácia da classificação das observações originais e na externa confirmaram-se os resultados da interna.

Cada variável utilizada na obtenção da função discriminante foi testada pelo método de Wilk's Lambda (que é uma variação do teste F-ANOVA) ao nível de 5\% (Hair Jr. et al., 1998). 0 método de Wilk's Lambda testa a igualdade dos centroides dos grupos de variáveis, nos quais valores próximos de zero indicam forte diferença entre as médias, sendo, portanto, os mais adequados (Mário, 2014). Este método, juntamente com o teste qui-quadrado, também foi utilizado para testar a significância das funções discriminantes.

A matriz de covariância para cada grupo de variáveis auxilia na percepção da homogeneidade de covariância entre grupos de variáveis, um dos pressupostos da análise discriminante (Mário, 2014). Esta homogeneidade foi testada a partir da estatística Box's M ao nível de 5\%.

Os resultados foram discutidos com base em trabalhos anteriores na área que utilizaram outras metodologias. Lucena et al. (2004) abordaram a migração de constituintes iônicos no meio saturado em subsuperfície, particularmente nitrogênio e potássio; Machado et al. (2004) calcularam a transferência molar de minerais entre a água mineralizada e o meio, ocorrida entre os sistemas aquíferos Superior e Médio da Chapada do Araripe; Machado (2005) corroborou com os principais processos geoquímicos da formação das águas subterrâneas; Franca et al. (2006) apresentaram uma simulação computacional do transporte advectivo do contaminante de partículas do riacho dos macacos para o aquífero; e, Santos et al. (2014) modelaram o transporte de cloreto proveniente de esgoto urbano no aquífero sedimentar.

\section{Resultados e discussão}

Após o cálculo do balanço iônico, as análises laboratoriais apresentaram erros toleráveis, inferiores a 10\% (Logan, 1965), cujo mínimo foi de 0,80 \% (P11 - Crato) e o máximo de 9,89\% (P3 - Barbalha).

A estatística descritiva das concentrações e as medidas das variáveis físico-químicas estão na tabela 1.

\subsection{Análise fatorial}

Em uma avaliação prévia realizou-se uma análise fatorial considerando as 23 variáveis físico-químicas. Nesta análise verificou-se que o índice $K M O$ obtido para o conjunto de variáveis analisado foi de 0,456 e o teste estatístico de esfericidade de Bartlett não se mostrou significativo a $p<0,01$. Esses resultados indicaram que os fatores encontrados na análise fatorial não descreveram adequadamente a variação dos dados originais. Nesse contexto, cinco das 23 variáveis analisadas (salinidade, $\mathrm{Al}^{3+}, \mathrm{N}-\mathrm{NO}_{2}^{-}, \mathrm{CO}_{2}$ livre e OD) apresentaram baixa comunalidade (inferior a 0,600 ).

As 18 variáveis restantes foram utilizadas numa segunda simulação, na qual verificou-se que o índice $K M O$ permaneceu baixo e o teste estatístico de esfericidade de Bartlett continuou sem significância. Nessa simulação, três das 18 variáveis restantes $\left(\mathrm{F}^{-}, \mathrm{N}-\mathrm{NH}_{3}^{+} \mathrm{e} \mathrm{pH}\right)$ continuaram apresentando baixa comunalidade.

Em uma terceira simulação, as três variáveis que apresentaram baixa comunalidade foram desconsideradas e o modelo apresentou resultado favorável para os 15 restantes, com índice $K M O$ de 0,759 e teste de esfericidade de Bartlett significa- 
Tabela 1. Estatística descritiva das concentrações e medidas das variáveis físico-químicas, com n = 23.

Table 1. Descriptive statistics of concentrations and measurements of physico-chemical variables, with $n=23$.

\begin{tabular}{|c|c|c|c|c|}
\hline Variável & $\boldsymbol{x}_{\min }$ & $x_{\max }$ & $\overline{\bar{x}}$ & $c v$ \\
\hline $\mathrm{Ca}^{2+}$ & 0,08 & 66,85 & 26,75 & 68,82 \\
\hline $\mathrm{Mg}^{2+}$ & 0,01 & 29,45 & 8,50 & 85,88 \\
\hline $\mathrm{Na}^{+}$ & 1,00 & 103,00 & 40,10 & 65,74 \\
\hline $\mathrm{K}^{+}$ & 1,00 & 19,00 & 8,20 & 66,95 \\
\hline $\mathrm{HCO}_{3}^{-}$ & 6,41 & 173,57 & 64,56 & 67,13 \\
\hline $\mathrm{Cl}^{-}$ & 5,03 & 65,10 & 30,26 & 56,18 \\
\hline $\mathrm{SO}_{4}^{2-}$ & 0,38 & 161,15 & 31,74 & 127,85 \\
\hline $\mathrm{Al}_{3}^{+}$ & 0,01 & 2,35 & 0,38 & 200,00 \\
\hline $\mathrm{F}^{-}$ & 0,01 & 4,51 & 0,17 & 482,35 \\
\hline $\mathrm{N}-\mathrm{NH}_{3}^{+}$ & 0,08 & 1,22 & 0,25 & 84,00 \\
\hline $\mathrm{N}-\mathrm{NO}_{2}^{-}$ & 0,01 & 0,01 & 0,01 & 0,00 \\
\hline $\mathrm{N}-\mathrm{NO}_{3}^{-}$ & 0,01 & 9,22 & 3,04 & 78,62 \\
\hline $\mathrm{P}^{-\mathrm{PO}_{4}{ }_{4}^{3-}}$ & 0,05 & 7,32 & 0,68 & 195,59 \\
\hline Fe total & 0,01 & 4,51 & 0,17 & 482,35 \\
\hline $\mathrm{CO}_{2}$ livre & 24,00 & 100,00 & 83,57 & 30,97 \\
\hline Dureza Total & 0,20 & 287,24 & 100,86 & 70,29 \\
\hline $\mathrm{pH}$ & 4,33 & 6,89 & 5,88 & 10,71 \\
\hline $\mathrm{CE}$ & 61,00 & 803,00 & 334,57 & 52,40 \\
\hline Salinidade & 0,01 & 0,02 & 0,01 & 0,00 \\
\hline STD & 57,81 & 574,88 & 249,36 & 47,24 \\
\hline Oxigênio Dissolvido & 4,03 & 5,04 & 4,38 & 5,71 \\
\hline Turbidez & 0,04 & 27,80 & 1,22 & 414,75 \\
\hline Cor & 1,00 & 375,00 & 15,10 & 451,19 \\
\hline
\end{tabular}

Concentrações em mg/L; CE: condutividade elétrica ( $\mu \mathrm{S} / \mathrm{cm})$; salinidade (\%);

STD: sólidos totais dissolvidos (mg/L); turbidez (UT); cor (UH); ${ }^{x_{\min }}$ : valor mínimo; ${ }^{x_{\max }}$ : valor máximo; ${ }^{\bar{x}}$ : valor médio; ${ }^{c v}$ : coeficiente de variação (\%).

tivo a $\mathrm{p}<0,01$.

As tabelas 2 e 3 mostraram, respectivamente, a matriz de correlação para as variáveis analisadas na terceira simulação e a análise fatorial dos dados, com três fatores de autovalores superiores a um. A matriz de correlação mostra que dos 105 coeficientes de correlação, aproximadamente $55 \%$ do total de pares apresentaram valores significativos. Destes, cerca de $74 \%$ encontram-se no intervalo $0,6 \leq|\mathrm{r}|<1,0$, caracterizados, segundo Callegari-Jacques (2003), como de correlação forte. 0 restante $(26 \%)$ encontra-se no intervalo $0,3 \leq|\mathrm{r}|<0,6$, caracterizados como de correlação moderada. A análise fatorial mostra que o primeiro fator apresenta uma contribuição para explicação da variância total das variáveis de aproximadamente $48 \%$, o segundo de $27 \%$ e o terceiro $10 \%$. Estes resultados indicam que os três fatores respondem por aproximadamente $85 \%$ da variância total dos dados.

A matriz de correlação (Tab. 2) indica que a CE e STD (resultante direto da CE) possuem corre- lações fortes com $\mathrm{HCO}_{3}{ }^{-}, \mathrm{Ca}^{2+}, \mathrm{Mg}^{2+}, \mathrm{K}^{+}, \mathrm{Na}^{+}, \mathrm{Cl}^{-}, \mathrm{SO}_{4}^{2-}$ e DT (dureza total), mostrando o enriquecimento iônico das águas subterrâneas através da relação tempo de contato da água com o litotipo. Assim, se há interferência de fontes antrópicas, certamente o tempo de contato com os litotipos explica a concentração iônica das águas. Com exceção do $\mathrm{Cl}^{-}$, todas as variáveis compõem o Fator 1 da análise fatorial (Tab. 3).

A maioria dos poços amostrados (70\%) está locada na Formação Rio da Batateira (Fig. 2), que é caracterizada por arenitos argilosos. Os principais minerais presentes nestes arenitos são o quartzo $\left(\mathrm{SiO}_{2}\right)$, os feldspatos potássicos $\left(\mathrm{KAlSi}_{3} \mathrm{O}_{8}\right)$ e as micas $\left(\mathrm{KAl}_{2} \mathrm{Si}_{3} \mathrm{AlO}_{10}(\mathrm{OH}, \mathrm{F})_{2}\right)$. Segundo Machado et al. (2004), nas camadas argilosas é possível encontrar a presença de íons $\left(\mathrm{Ca}^{2+}, \mathrm{Mg}^{2+}, \mathrm{Na}^{+}\right.$e $\left.\mathrm{K}^{+}\right)$ adsorvidos, que podem ser liberados para a água através de trocas iônicas. Na Chapada do Araripe, a Formação Rio da Batateira está sotoposta à Formação Santana, que é caracterizada por camadas de calcita $\left(\mathrm{CaCO}_{3}\right)$, gipsita $\left(\mathrm{CaSO}_{4}\right)$ e anidrita 
Tabela 2. Matriz de correlação das variáveis físico-químicas das águas subterrâneas, com destaque para as correlações fortes. Table 2. Matrix of correlation of physical-chemical variables of groundwater, with emphasis on the strong correlations.

\begin{tabular}{|c|c|c|c|c|c|c|c|c|c|c|c|c|c|c|c|}
\hline Variáveis & $\mathrm{HCO}_{3}^{-}$ & $\mathrm{Ca}^{2+}$ & $\mathrm{Cl}^{-}$ & CE & DT & Fe total & $\mathrm{Mg}^{2+}$ & $\mathrm{N}-\mathrm{NO}_{3}^{-}$ & $\mathbf{K}^{+}$ & $\mathrm{Na}^{+}$ & STD & $\mathbf{T}$ & $\mathrm{P}-\mathrm{PO}_{4}{ }^{3-}$ & $\mathrm{SO}_{4}{ }^{2-}$ & C \\
\hline $\mathrm{HCO}_{3}^{-}$ & 1,00 & & & & & & & & & & & & & & \\
\hline $\mathrm{Ca}^{2+}$ & $0,72^{*}$ & 1,00 & & & & & & & & & & & & & \\
\hline $\mathrm{Cl}^{-}$ & $0,26^{*}$ & $0,37^{*}$ & 1,00 & & & & & & & & & & & & \\
\hline $\mathrm{CE}$ & $0,65^{*}$ & $0,81^{*}$ & $0,70^{*}$ & 1,00 & & & & & & & & & & & \\
\hline DT & $0,71^{*}$ & $0,95^{*}$ & $0,43^{*}$ & $0,81^{*}$ & 1,00 & & & & & & & & & & \\
\hline Fe total & 0,16 & $-0,01$ & $-0,17$ & $-0,07$ & $-0,00$ & 1,00 & & & & & & & & & \\
\hline $\mathrm{Mg}^{2+}$ & $0,56^{*}$ & $0,73^{*}$ & $0,43^{*}$ & $0,66^{*}$ & $0,90^{*}$ & 0,00 & 1,00 & & & & & & & & \\
\hline $\mathrm{N}-\mathrm{NO}_{3}^{-}$ & $-0,50 *$ & $-0,44^{*}$ & $0,60^{*}$ & $-0,15$ & $-0,35^{*}$ & $-0,24$ & $-0,18$ & 1,00 & & & & & & & \\
\hline $\mathrm{K}^{+}$ & $0,36^{*}$ & $0,52^{*}$ & $0,66^{*}$ & $0,81^{*}$ & $0,59 *$ & $-0,00$ & $0,57^{*}$ & $-0,01$ & 1,00 & & & & & & \\
\hline $\mathrm{Na}^{+}$ & $0,72^{*}$ & $0,76^{*}$ & $0,64^{*}$ & $0,94^{*}$ & $0,75^{*}$ & 0,08 & $0,58^{*}$ & $-0,27 *$ & $0,76^{*}$ & 1,00 & & & & & \\
\hline STD & $0,66^{*}$ & $0,82^{*}$ & $0,69^{*}$ & $1,00 *$ & $0,81^{*}$ & $-0,07$ & $0,66^{*}$ & $-0,17$ & $0,80^{*}$ & $0,94^{*}$ & 1,00 & & & & \\
\hline $\mathrm{T}$ & 0,20 & $-0,00$ & $-0,13$ & $-0,06$ & 0,01 & $0,99^{*}$ & 0,01 & $-0,26^{*}$ & 0,03 & 0,12 & $-0,06$ & 1,00 & & & \\
\hline $\mathrm{P}-\mathrm{PO}_{4}^{3-}$ & 0,25 & 0,03 & $-0,09$ & $-0,03$ & 0,06 & $0,94^{*}$ & 0,09 & $-0,29 *$ & 0,09 & 0,16 & $-0,03$ & $0,96^{*}$ & $\quad 1,00$ & & \\
\hline $\mathrm{SO}_{4}{ }^{2-}$ & $0,58^{*}$ & $0,70^{*}$ & 0,25 & $0,75^{*}$ & $0,61^{*}$ & 0,14 & $0,37^{*}$ & $-0,40^{*}$ & $0,50^{*}$ & $0,72^{*}$ & $0,77^{*}$ & 0,13 & 0,13 & 1,00 & \\
\hline $\mathrm{C}$ & 0,17 & 0,01 & $-0,16$ & $-0,06$ & 0,01 & $1,00^{*}$ & 0,01 & $-0,24$ & 0,00 & 0,09 & $-0,06$ & $0,99 *$ & $0,95^{*}$ & 0,15 & 1,00 \\
\hline
\end{tabular}

CE: condutividade elétrica; DT: dureza total; STD: sólidos totais dissolvidos; T: turbidez; C: cor.

* valores significativos com $\mathrm{p}<0,05$.

Tabela 3. Cargas fatoriais, comunalidades e variância explicada na análise fatorial das quinze variáveis analisadas, após a rotação pelo método varimax.

Table 3. Factor loadings, commonalities and explained variance in the factor analysis of the fifteen variables analyzed, after rotation by varimax method.

\begin{tabular}{|c|c|c|c|c|}
\hline Variável & Fator 1 & Fator 2 & Fator 3 & Comunalidade \\
\hline $\mathrm{HCO}_{3}^{-}$ & 0,760 & 0,160 & $-0,356$ & 0,729 \\
\hline $\mathrm{Ca}^{2+}$ & 0,903 & $-0,043$ & $-0,280$ & 0,895 \\
\hline $\mathrm{Cl}^{-}$ & 0,609 & $-0,099$ & 0,659 & 0,815 \\
\hline $\mathrm{CE}$ & 0,965 & $-0,058$ & 0,187 & 0,970 \\
\hline DT & 0,914 & $-0,026$ & $-0,175$ & 0,867 \\
\hline Fe total & $-0,006$ & 0,990 & $-0,081$ & 0,986 \\
\hline $\mathrm{Mg}^{2+}$ & 0,769 & $-0,003$ & $-0,017$ & 0,601 \\
\hline $\mathrm{N}-\mathrm{NO}_{3}^{-}$ & $-0,320$ & $-0,206$ & 0,796 & 0,778 \\
\hline $\mathrm{K}^{+}$ & 0,762 & 0,057 & 0,440 & 0,778 \\
\hline $\mathrm{Na}^{+}$ & 0,929 & 0,113 & 0,120 & 0,890 \\
\hline STD & 0,968 & $-0,060$ & 0,163 & 0,966 \\
\hline $\mathrm{T}$ & 0,015 & 0,995 & $-0,067$ & 0,995 \\
\hline $\mathrm{P}-\mathrm{PO}_{4}{ }^{3-}$ & 0,065 & 0,970 & $-0,071$ & 0,950 \\
\hline $\mathrm{SO}_{4}^{2-}$ & 0,761 & 0,118 & $-0,203$ & 0,635 \\
\hline $\mathrm{C}$ & 0,004 & 0,990 & $-0,079$ & 0,986 \\
\hline $\begin{array}{l}\text { Variância explicada } \\
\text { pelo fator }(\%)\end{array}$ & 48,060 & 27,465 & 10,028 & - \\
\hline
\end{tabular}

Variância acumulada (\%)

85,553

CE: condutividade elétrica; DT: dureza total; STD: sólidos totais dissolvidos; T: turbidez; C: cor.

$\left(\mathrm{CaSO}_{4} \cdot 2 \mathrm{H}_{2} \mathrm{O}\right)$, de elevada solubilidade, além de folhelhos argilosos e betuminosos. As águas que percolam esta formação, enriquecidas nos íons $\mathrm{Ca}^{2+} \mathrm{e} \mathrm{SO}_{4}^{2-}$ e fortemente correlacionados com o íon $\mathrm{HCO}_{3}{ }^{-}$, chegam ao aquífero Rio da Batateira e se misturam com águas recarregadas no Vale do Cariri. Estes processos contribuem com uma elevação dos sólidos totais dissolvidos e com a salinidade das águas explotadas no Vale do Cariri (Tab. 4).

$\mathrm{O}$ íon $\mathrm{Cl}^{-}$(com concentrações de até 65,10 $\mathrm{mg} / \mathrm{L}$ ) correlacionou-se positivamente com os íons $\mathrm{NO}_{3}^{-}, \mathrm{K}^{+}$e $\mathrm{Na}^{+}$e com a CE (com valor máximo de $803 \mu \mathrm{S} / \mathrm{cm}$ ), apontando mais uma vez a relação desses íons com o aumento da salinidade dessas 


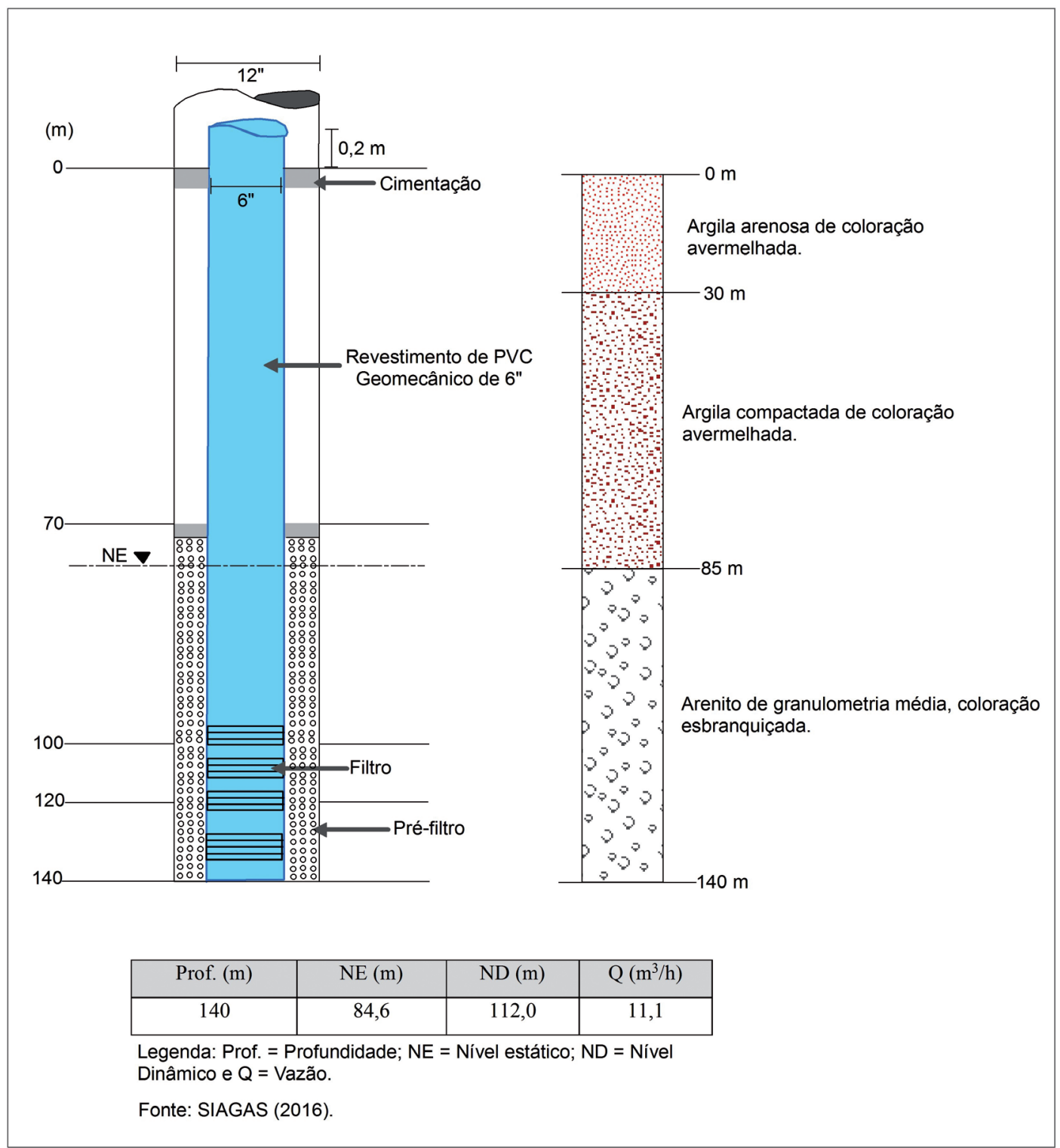

Figura 2. Perfil construtivo / litológico do poço P29 (Juazeiro do Norte) - Aquífero Rio da Batateira.

Figure 2. Constructive / lithological profile of well P29 (Juazeiro do Norte) - Aquifer Rio da Batateira.

Tabela 4. Processos hidrogeoquímicos ocorridos nos sistemas aquíferos da Chapada do Araripe, parte da Bacia Sedimentar do Araripe (Machado et al., 2004).

Table 4. Hydrogeochemical processes in the aquifer systems of the Araripe Plateau, part of the Araripe Sedimentary Basin (Machado et al., 2004).

\begin{tabular}{|c|c|c|c|c|c|c|c|c|c|c|c|}
\hline \multirow[b]{2}{*}{ Amostra } & \multirow[b]{2}{*}{ pH } & \multirow{2}{*}{$\mathrm{T}\left({ }^{\circ} \mathrm{C}\right)$} & \multirow{2}{*}{$\mathrm{CE}(\mu \mathrm{S} / \mathrm{cm})$} & \multicolumn{8}{|c|}{ Concentrações em mmol/L } \\
\hline & & & & $\mathrm{Ca}^{2+}$ & $\mathrm{Mg}^{2+}$ & $\mathrm{Na}^{+}$ & $\mathbf{K}^{+}$ & $\mathrm{Fe}^{2+}$ & $\mathrm{Cl}^{-}$ & $\mathrm{SO}_{4}=$ & $\mathrm{HCO}_{3}{ }^{-}$ \\
\hline Inicial & 6,0 & 26,8 & 40 & 0,18 & 0,15 & 0,65 & 0,12 & - & 0,91 & 0,009 & 0,35 \\
\hline Final & 7,3 & 39,8 & 904 & 3,22 & 2,45 & 2,48 & 0,41 & 0,02 & 1,77 & 3,91 & 4,12 \\
\hline
\end{tabular}

águas. Destes íons, apenas o $\mathrm{Cl}^{-}$e o $\mathrm{NO}_{3}^{-}$encontram-se agrupados em um único fator da análise fatorial (Fator 3), indicando a possível relação destes íons com fontes de poluição de origem orgânica. Na área é comum o lançamento de efluentes não tratados em rios e riachos, contribuindo com o aporte dos íons nitrato e cloretos nas águas superficiais, que por conexão recarregam os aquíferos. Lucena et al. (2004) corroboram que, ao atingir o aquífero, estes íons podem adquirir uma razoável mobilidade, capaz de alcançar eventualmente áreas que teoricamente seriam de baixo risco de contaminação. Neste contexto, Santos et al. (2014) utilizaram o íon $\mathrm{Cl}^{-}$como traçador no estudo da conexão hidráulica entre um riacho perenizado por esgoto e o aquífero explotado pela bateria de poços do sistema de abastecimento público de Juazeiro do Norte. Os resultados mostraram que o transporte 
de contaminante ocorre, predominantemente, na vertical, induzido pelo bombeamento dos poços e pela recarga do aquífero a partir do riacho. Nesta mesma bateria de poços, Franca et al. (2006) também observaram que as águas explotadas por parte dos poços apresentaram indícios de poluição por esgotos domésticos. Machado (2005) verificou uma forte correlação entre as concentrações de nitrato com cloreto e com CE de amostras de águas subterrâneas coletadas nos municípios de Juazeiro do Norte e Crato. Segundo o autor, elevados valores de CE, nestas condições, pode ser um indicativo de contaminação por esgoto doméstico.

O Fe total (de até $4,51 \mathrm{mg} / \mathrm{L}$ ) correlacionou-se fortemente $(>0,90) \mathrm{com}$ a turbidez e a cor; no entanto, a forte correlação com o íon $\mathrm{PO}_{4}^{3-}$ sugere influência antropogênica na composição química dessas águas (com $\mathrm{P}^{-} \mathrm{PO}_{4}{ }^{3-}$ de até 7,32 mg/L). Estas variáveis estão agrupadas no Fator 2 da análise fatorial.

O Fe total está presente em baixas concentrações $(<0,3 \mathrm{mg} / \mathrm{L})$ em quase todas as águas subterrâneas e ocorre sob diversas formas químicas. Suas fontes são minerais ferro-magnesianos. No estado ferroso $\left(\mathrm{Fe}^{2+}\right)$ forma composto solúveis, principalmente hidróxidos e em ambientes oxidantes, o $\mathrm{Fe}^{2+}$ passa a $\mathrm{Fe}^{3+}$, dando origem ao hidróxido férrico, que é insolúvel e precipita, elevando a turbidez e causando uma coloração avermelhada à água, comumente designada de "capa rosa". Os elevados valores de $\mathrm{P}_{-} \mathrm{PO}_{4}^{3-}$, acima de 1,0 mg/L (Santos, 2008), indicam uma possível mistura entre as águas naturais do aquífero com águas poluídas.

\subsection{Análise de agrupamento hierárquico}

A técnica de análise de agrupamento hierárquico, aplicada as variáveis explicadas pelos Fatores 1, 2 e 3 da análise fatorial, agrupou as amostras com características semelhantes, ou seja, águas quimicamente similares (Fig. 3). Os grupos obtidos e as variáveis que os geraram foram submetidos à análise de variância One-Way ANOVA e apresentaram níveis de significância inferiores a 5\%, indicando a formação de um conjunto relativamente estável de grupos. 0 número de grupos por fator foi definido pela primeira grande diferença entre os coeficientes reescalonados de agrupamento. Esses coeficientes explicitaram o ponto de corte cinco (maior precisão), onde se observou a formação de quatro grupos homogêneos no Fator 1 e dois grupos nos Fatores 2 e 3.

As variáveis do Fator $1\left(\mathrm{HCO}_{3}{ }^{-}, \mathrm{Ca}^{2+}, \mathrm{Mg}^{2+}, \mathrm{K}^{+}\right.$, $\mathrm{Na}^{+}, \mathrm{SO}_{4}{ }^{2-}, \mathrm{CE}, \mathrm{STD}$ e DT) (Fig. 3A) geraram 4 grupos similares: o primeiro e o segundo, cada um com- posto por 33,3\% das amostras (10 poços), o terceiro, por $23,3 \%$ (7 poços) e o quarto, por $10,0 \%$ (3 poços). As variáveis utilizadas na caracterização do Fator 1 atenderam aos padrões de potabilidade definidos na Portaria № 2914/2011 do Ministério da Saúde.

O Grupo 1 (10 poços) é caracterizado pelas baixas concentrações de sais $(61 \mu \mathrm{S} / \mathrm{cm} \leq \mathrm{CE} \leq 239$ $\mu \mathrm{S} / \mathrm{cm}$ ) e com águas de melhor qualidade. As concentrações de STD variaram de 57,8 mg/L, no poço 29 (colunas filtrantes de 92 a 100 m; 104 a 112 m; 116 a $124 \mathrm{~m}$ e 128 a $136 \mathrm{~m}$ ) a $183,9 \mathrm{mg} / \mathrm{L}$, no poço 16 , com colunas filtrantes oscilando de 40 a $44 \mathrm{~m}$; 48 a $56 \mathrm{~m} ; 60$ a $68 \mathrm{~m}$ e 72 a $80 \mathrm{~m}$. A DT $\left(\mathrm{CaCO}_{3}\right)$ oscilou de $0,2 \mathrm{mg} / \mathrm{L}$, no poço 29 , a 63,3 $\mathrm{mg} / \mathrm{L}$, no 12 (colunas filtrantes de 44 a $48 \mathrm{~m} ; 56$ a $72 \mathrm{~m}$; 80 a 88 m e 92 a $104 \mathrm{~m}$ ). As maiores concentrações de $\mathrm{Na}^{+}$ e $\mathrm{SO}_{4}{ }^{2-}$ foram de, respectivamente, $29,0 \mathrm{mg} / \mathrm{L}$, no poço 26 (sem informação da posição das colunas filtrantes) e 16,5 mg/L, no 12 . As concentrações de $\mathrm{HCO}_{3}$; variaram de $16,6 \mathrm{mg} / \mathrm{L}$, no poço 13 , a 73,3 $\mathrm{mg} / \mathrm{L}$, no 26, ambos com ausência de informação do posicionamento das colunas filtrantes. As maiores concentrações dos íons $\mathrm{Ca}^{2+}, \mathrm{Mg}^{2+}$ e $\mathrm{K}^{+}$foram de respectivamente $25,5 \mathrm{mg} / \mathrm{L}$, no poço 12 , 8,8 e 8,0 $\mathrm{mg} / \mathrm{L}$, ambas no 16.

O Grupo 2 (10 poços) é caracterizado por águas de salinidade intermediária $(253 \mu \mathrm{S} / \mathrm{cm} \leq$ $\mathrm{CE} \leq 422 \mu \mathrm{S} / \mathrm{cm}$ ) e de boa qualidade. As concentrações de STD variaram de 194,7 mg/L, no poço 11 a 302,2 mg/L, no 19, ambos também com ausência de informação do posicionamento dos filtros. A DT $\left(\mathrm{CaCO}_{3}\right.$ ) oscilou de $0,2 \mathrm{mg} / \mathrm{L}$, no poço 19 , a 63,3 $\mathrm{mg} / \mathrm{L}$, no 2 , com posicionamento dos filtros variando de 48 a $66 \mathrm{~m}$ e 72 a $102 \mathrm{~m}$. As maiores concentrações dos íons $\mathrm{Na}^{+}$e $\mathrm{SO}_{4}^{2-}$ foram de $50,0 \mathrm{mg} / \mathrm{L}$, no poço 22 (colunas filtrantes variando de 40 a 56 $\mathrm{m}$ e 72 a $98 \mathrm{~m}$ ) e $88,7 \mathrm{mg} / \mathrm{L}$, no 4 (com filtros posicionados em 30 a $48 \mathrm{~m}$; 54 a 72 e 78 a $96 \mathrm{~m}$ ). As concentrações de $\mathrm{HCO}_{3}^{-}$; variaram de $6,4 \mathrm{mg} / \mathrm{L}$, no poço 15 (sem informação do posicionamento das colunas filtrantes), a 97,7 mg/L, no 22 (filtros de 40 a $56 \mathrm{~m}$ e 72 a $98 \mathrm{~m}$ ). As maiores concentrações dos íons $\mathrm{Ca}^{2+}, \mathrm{Mg}^{2+}$ e $\mathrm{K}^{+}$foram de respectivamente $44,5 \mathrm{mg} / \mathrm{L}$, no poço 18 (sem informação da posição dos filtros), $12,4 \mathrm{mg} / \mathrm{L}$, no 17 (filtros de 32 a 36 $\mathrm{m} ; 44$ a $52 \mathrm{~m}$ e 56 a $64 \mathrm{~m}$ ) e $12,0 \mathrm{mg} / \mathrm{L}$, no 15 (sem informação da posição dos filtros).

0 Grupo 3 (7 poços) é caracterizado por águas de salinidade também intermediária $(398 \mu \mathrm{S} / \mathrm{cm}$ $\leq \mathrm{CE} \leq 546 \mu \mathrm{S} / \mathrm{cm}$ ), porém ligeiramente mais mineralizadas do que as do Grupo 2. As concentrações de STD variaram de $284,9 \mathrm{mg} / \mathrm{L}$, no poço 7 (sem informação do posicionamento dos filtros), a $390,9 \mathrm{mg} / \mathrm{L}$, no 6 (coluna filtrante de 18 a $54 \mathrm{~m}$ ). 


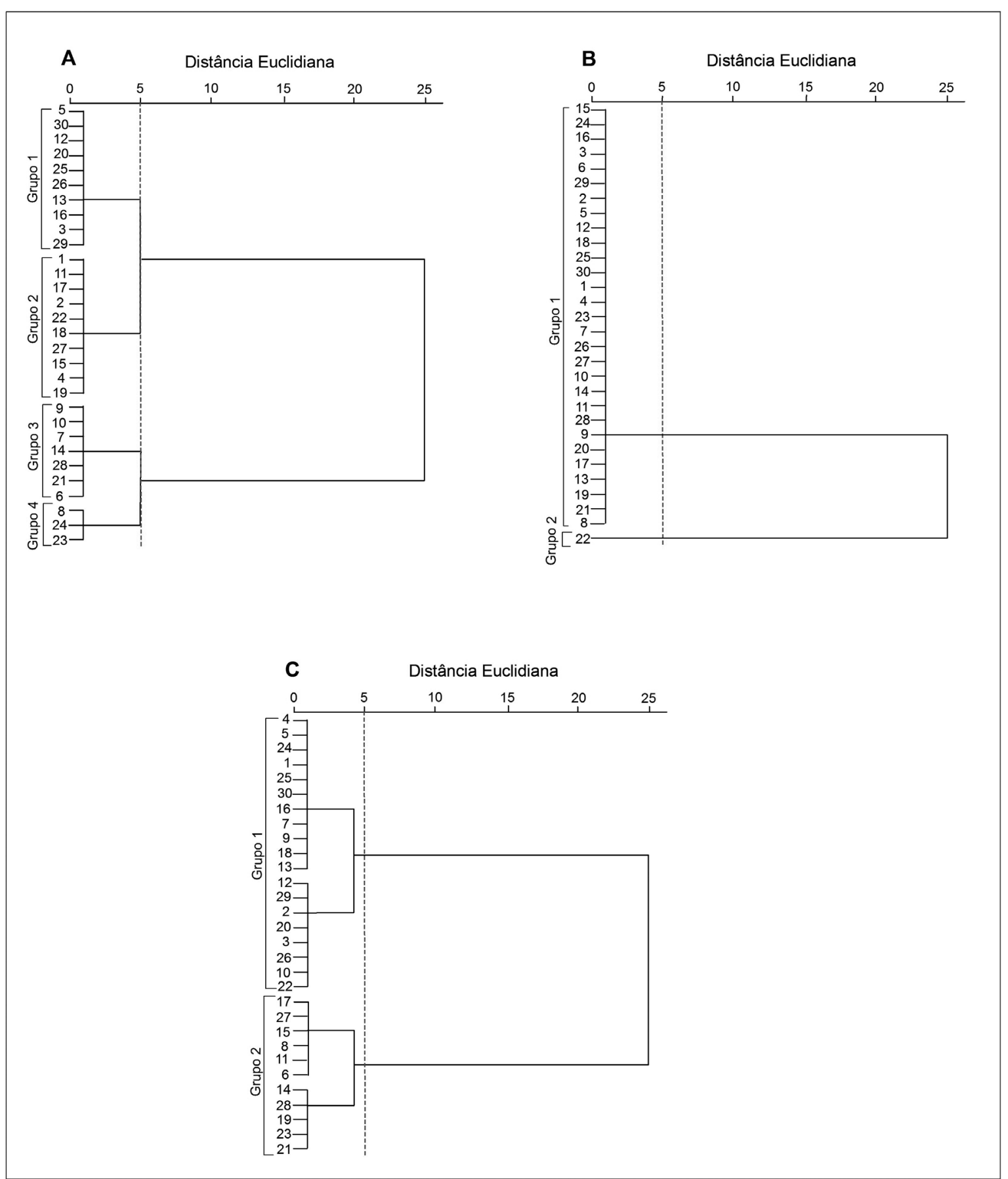

Figura 3. Dendrogramas resultante da análise de agrupamento hierárquico das variáveis explicadas nos Fatores 1 (A), 2 (B) e 3 (C).

Figure 3. Resulting dendrogram of hierarchical cluster analysis of variables explained in Factor 1 (A), 2 (B) and 3 (C).

A DT $\left(\mathrm{CaCO}_{3}\right)$ oscilou de $130,7 \mathrm{mg} / \mathrm{L}$, no poço 28 (sem informação da posição dos filtros), a 253,9 $\mathrm{mg} / \mathrm{L}$, no 6. As maiores concentrações dos íons $\mathrm{Na}^{+}$e $\mathrm{SO}_{4}{ }^{2-}$ foram de respectivamente $84,0 \mathrm{mg} / \mathrm{L}$, no poço 21 e $56,9 \mathrm{mg} / \mathrm{L}$, no 7, ambos sem informação da posição dos filtros. As concentrações de $\mathrm{HCO}_{3}$, variaram de $31,5 \mathrm{mg} / \mathrm{L}$, no poço 9 (colunas filtrantes de 36 a $40 \mathrm{~m} ; 56$ a $64 \mathrm{~m}$ e 72 a $76 \mathrm{~m}$ ) a $159,6 \mathrm{mg} / \mathrm{L}$, no 21. As maiores concentrações dos íons $\mathrm{Ca}^{2+}, \mathrm{Mg}^{2+} \mathrm{e} \mathrm{K}^{+}$foram de respectivamente 59,5 e 25,8 mg/L, no poço 6 (coluna filtrante de 18 a 54 m) e $19,0 \mathrm{mg} / \mathrm{L}$, no 14 (colunas filtrantes de $36 \mathrm{a}$ $52 \mathrm{~m}$ e 60 a $76 \mathrm{~m}$ ).
0 Grupo 4 (3 poços) é caracterizado por águas de maior salinidade $(616 \mu \mathrm{S} / \mathrm{cm} \leq \mathrm{CE} \leq 803 \mu \mathrm{S} /$ $\mathrm{cm})$. As concentrações de STD variaram de 441,0 $\mathrm{mg} / \mathrm{L}$, no poço 24 (sem informação do posicionamento dos filtros) a $574,9 \mathrm{mg} / \mathrm{L}$, no 23 (filtros variando de 70 a $82 \mathrm{~m})$. A DT $\left(\mathrm{CaCO}_{3}\right)$ variou de $151,8 \mathrm{mg} / \mathrm{L}$, no poço 24 , a $287,2 \mathrm{mg} / \mathrm{L}$, no 8 , ambos sem informação da posição dos filtros. As maiores concentrações dos íons $\mathrm{Na}^{+}$e $\mathrm{SO}_{4}{ }^{2-}$ foram de respectivamente 103,0 e $161,2 \mathrm{mg} / \mathrm{L}$, no poço 23 . As concentrações de $\mathrm{HCO}_{3}{ }^{-}$, variaram de $118,3 \mathrm{mg} / \mathrm{L}$, no poço 23 , a $173,6 \mathrm{mg} / \mathrm{L}$, no 24 . As maiores concentrações dos íons $\mathrm{Ca}^{2+}, \mathrm{Mg}^{2+}$ e $\mathrm{K}^{+}$foram de res- 
pectivamente 66,9 e $29,5 \mathrm{mg} / \mathrm{L}$, no poço 8 e 10,3 $\mathrm{mg} / \mathrm{L}$, no 23.

As variáveis do Fator 1 indicam que os poços do Grupo 1 explotam águas menos mineralizadas do aquífero Rio da Batateira, com recarga predominante no vale do Cariri, enquanto que os do Grupo 4, com águas mais mineralizadas, tiveram forte contribuição de águas que percolaram a Formação Santana. As águas dos demais Grupos (2 e 3) são caracterizadas hidroquimicamente como uma mistura das águas dos Grupos 1 e 4. Diferente dos demais poços, o poço 18 (do Grupo 2) explota o aquífero Arajara, localizado sobreposto à Formação Santana.

As variáveis do Fator 2 (Fe total, $\mathrm{P}_{-} \mathrm{PO}_{4}{ }^{3-}$, turbidez e cor) (Fig. 3B) geraram dois grupos similares: o primeiro composto por 97\% das amostras (29 poços) e o segundo, por apenas 3\% (1 poço).

O Grupo 1 (29 poços) é caracterizado por águas que atendem aos padrões de potabilidade definidos na Portaria № 2914/2011 do Ministério da Saúde, quanto à concentração de Fe total e à turbidez, com valores máximos de respectivamente $0,2 \mathrm{mg} / \mathrm{L}$, no poço 8 e 3,6 UT, no 21 . A concentração máxima de $\mathrm{P}^{-} \mathrm{PO}_{4}{ }^{3-}$ foi de $2,1 \mathrm{mg} / \mathrm{L}$, no poço 21 e a cor máxima de $23 \mathrm{UH}$, no 8.

0 Grupo 2, representado apenas pelo poço 22, explota água que não atende aos padrões de potabilidade, quanto à concentração de Fe total, de 4,5 mg/L e à turbidez, de 27,8 UT. A cor da água explotada nesse poço apresenta aspecto turvo, com 375 UH e a concentração de $\mathrm{P}_{-} \mathrm{PO}_{4}{ }^{3-}$ foi de 7,3 $\mathrm{mg} / \mathrm{L}$, indicando forte influência antropogênica na sua composição.

As variáveis do Fator $3\left(\mathrm{Cl}^{-}\right.$e N-NO$\left.{ }_{3}^{-}\right)$(Fig. 3C) geraram dois grupos similares: o primeiro composto por $63 \%$ das amostras (19 poços) e o segundo por 37\% (11 poços).

O Grupo 1 (19 poços) é representado por águas que atendem aos padrões de potabilidade definidos na Portaria № 2914/2011 do Ministério da Saúde, quanto às concentrações de $\mathrm{Cl}^{-} \mathrm{e} \mathrm{N}-\mathrm{NO}_{3}{ }^{-}$, que atingiram valores máximos de respectivamente $31,4 \mathrm{mg} / \mathrm{L}$, no poço 13 e 9,2 mg/L, no 16 .

O Grupo 2 (11 poços) também é representado por águas que atendem aos padrões de potabilidade, mas com concentrações de $\mathrm{Cl}^{-}$superiores as do Grupo 1. As concentrações de $\mathrm{Cl}^{-}$e $\mathrm{N}-\mathrm{NO}_{3}^{-}$ atingiram valores máximos de respectivamente 65,1 mg/L, no poço 28 e 7,0 mg/L, no 19. A forte correlação entre estas variáveis ( $R=0,6$ na tab. 2$)$ sugere mistura entre as águas naturais do aquífero e águas de recarga proveniente de esgotos de origem orgânica.

\subsection{Análise discriminante}

Na análise discriminante utilizou-se apenas as variáveis do Fator 1, constituído de quatro grupos e nove variáveis. Os demais fatores não foram analisados; o 2 por apresentar dois grupos, sendo um deles constituído de apenas um elemento (poço), e o 3, por apresentar dois grupos com apenas duas variáveis. Dos 30 elementos (poços) disponíveis, $21(70 \%)$ foram utilizados no desenvolvimento da função e os demais, na validação externa (amostra de teste).

O baixo valor da estatística de Wilks'Lambda (Tab. 5) indicou que as variáveis CE e STD possuem o melhor poder de discriminação dentre as demais. Na Tabela 5 também encontram-se, para cada variável, os resultados do teste $F$-ANOVA com os respectivos níveis de significância (sig. < 0,05).

A partir da matriz de correlação (Tab. 2) também foi possível identificar prováveis casos de multicolinearidade, antecipando o conhecimento das variáveis que podem afetar o processo Stepwise. Nessa análise verificou-se correlações fortes entre as variáveis CE e STD, com 1,00 e $\mathrm{Ca}^{2+}$ e DT $\left(\mathrm{CaCO}_{3}\right)$, com 0,95 , sendo, portanto, excluída as duas últimas variáveis. 0 teste Box's $M$ apresentou o p-value (sig.) de 0,067, não rejeitando a hipótese da homogeneidade de covariância entre grupos de variáveis.

Das nove variáveis $\left(\mathrm{HCO}_{3}{ }^{-}, \mathrm{Ca}^{2+}, \mathrm{CE}, \mathrm{DT}, \mathrm{Mg}^{2+}\right.$, $\mathrm{K}^{+}, \mathrm{Na}^{+}, \mathrm{STD}$ e $\mathrm{SO}_{4}{ }^{2-}$ ), quatro foram consideradas discriminantes em cada passo da análise. No passo 1 considerou-se a variável STD, no 2, STD e $\mathrm{Mg}^{2+}$, no 3, STD, $\mathrm{Mg}^{2+} \mathrm{e} \mathrm{SO}_{4}{ }^{2-}$ e no 4, o STD, $\mathrm{Mg}^{2+}, \mathrm{SO}_{4}{ }^{2-}$ e $\mathrm{K}^{+}$. Nos quatro passos que o sistema produziu, obtiveram-se as melhores variáveis para a função discriminante, considerando-se sig. $<0,05$. As variáveis $\mathrm{HCO}_{3}^{-}, \mathrm{CE}, \mathrm{Ca}^{2+}$, DT e $\mathrm{Na}^{+}$apresentaram diferenças significativas nos quatro grupos, sendo, portanto, excluídas da análise.

Foram definidas três funções discriminantes para representar $100 \%$ da variância total. Observa-se na tabela 6 , que há predominância da primeira função discriminante, com autovalor de 73,775, variância de 98,9\% e correlação canônica de 0,993.

A primeira linha da tabela 7 mostra os testes de Wilks' Lambda e Qui-quadrado para as três funções discriminantes, indicando ser mais significativo. Considerando as demais análises (conjunto das funções 2 e 3, na segunda linha e apenas a função 3, na terceira), verifica-se um decréscimo no poder discriminatório, indicando que, dentre as três funções, a primeira é mais significativa.

As correlações entre as variáveis explicativas $\mathrm{Mg}^{2+}, \mathrm{SO}_{4}{ }^{2-}, \mathrm{STD}$ e $\mathrm{K}^{+}$e a função 1 foram de respec- 
tivamente $0,847,-0,785,-0,821$ e $-0,382$. Os coeficientes discriminantes (b) da função 1, expressa na equação 3 , mostra que $\mathrm{OMg}^{2+}$ é a variável mais importante, com $\mathrm{b}_{1}=0,527$, seguida do $\mathrm{K}^{+}$, com $\mathrm{b}_{4}$ $=-0,352$. Na área estes dois elementos podem estar relacionados a processos de troca iônica e intemperismo de feldspatos.

$$
\begin{gathered}
Z_{1}=0,527 \mathrm{Mg}^{2+}+0,031 \mathrm{SO}_{4}^{2-}+0,064 \mathrm{STD}- \\
0,352 \mathrm{~K}^{+}-17,137
\end{gathered}
$$

$\mathrm{O}$ íon $\mathrm{Mg}^{2+}$ participa do processo de troca iônica com o íon $\mathrm{Ca}^{2+}$ nas camadas argilosas do aquífero Rio da Batateira (Equações 4 e 5, com X representando as argilas). Na zona vadosa, a mobilidade do cátion $\mathrm{Mg}^{2+}$ dependerá da existência de alguns ânions na solução, particularmente do $\mathrm{NO}_{3}^{-}$e do $\mathrm{Cl}^{-}$, oriundos da mineralização da matéria orgânica (Pearson \& Vicent-Chandler, 1962; Gonzalez-Erico et al., 1979).

$$
\begin{aligned}
& \mathrm{Ca}^{2+}+2 \mathrm{X}^{-} \leftrightarrow \mathrm{CaX}_{2} \\
& \mathrm{Mg}^{2+}+2 \mathrm{X}^{-} \leftrightarrow \mathrm{MgX}_{2}
\end{aligned}
$$

$\mathrm{O}$ íon $\mathrm{K}^{+}$, juntamente com argilomineral caulinítico 1:1 $\left(\mathrm{Si}_{2} \mathrm{Al}_{2} \mathrm{O}_{5}(\mathrm{OH})_{4}\right)$ e o quartzo $\left(\mathrm{SiO}_{2}\right)$, predominantes na área (Silva, 2013), provavelmente são resultantes do processo de intemperismo gerado pela hidrólise parcial dos feldspatos (KAl$\mathrm{Si}_{3} \mathrm{O}_{8}$ ) (Eq. 6).

$$
\begin{gathered}
2 \mathrm{KAlSi}_{3} \mathrm{O}_{8}+11 \mathrm{H}_{2} \mathrm{O} \rightarrow \mathrm{Si}_{2} \mathrm{Al}_{2} \mathrm{O}_{5}(\mathrm{OH})_{4} \\
2 \mathrm{~K}^{+}+2 \mathrm{OH}^{-}
\end{gathered}
$$

Na validação interna, 95,2\% dos resultados foram bem classificados e na externa 66,7\%. Esse resultado mostra que esse modelo pode ser utilizado, com um bom nível de significância, na classificação dos elementos $\mathrm{Mg}^{2+}, \mathrm{SO}_{4}{ }^{2-}$, STD e $\mathrm{K}^{+}$.

Tabela 5. Teste de Igualdade das Médias do Grupo. Table 5. Medium Group of Equality Test.

\begin{tabular}{lccc}
\hline Variável & Wilks' Lambda & F-ANOVA & Sig. \\
\hline $\mathrm{HCO}_{3}{ }^{-}$ & 0,503 & 5,598 & 0,007 \\
$\mathrm{Ca}^{2+}$ & 0,379 & 9,285 & 0,001 \\
$\mathrm{CE}$ & 0,080 & 65,411 & 0,000 \\
$\mathrm{DT}$ & 0,225 & 19,493 & 0,000 \\
$\mathrm{Mg}^{2+}$ & 0,338 & 11,115 & 0,000 \\
$\mathrm{~K}^{+}$ & 0,298 & 13,349 & 0,000 \\
$\mathrm{Na}^{+}$ & 0,226 & 19,455 & 0,000 \\
$\mathrm{STD}^{+}$ & 0,070 & 75,305 & 0,000 \\
$\mathrm{SO}_{4}{ }^{2-}$ & 0,278 & 14,713 & 0,000 \\
\hline $\mathrm{Sig}^{-}$ & & &
\end{tabular}

Tabela 6. Autovalores e demais estatísticas das funções discriminantes.

Table 6. Eigenvalues and other statistics discriminant functions.

\begin{tabular}{ccccc}
\hline Função Autovalor & $\begin{array}{c}\text { \% de } \\
\text { Variância }\end{array}$ & $\begin{array}{c}\text { Cumulativo } \\
\text { \% }\end{array}$ & $\begin{array}{c}\text { Correlação } \\
\text { Canônica (R) }\end{array}$ \\
\hline 1 & 73,775 & 98,9 & 98,9 & 0,993 \\
2 & 0,811 & 1,1 & 100,0 & 0,669 \\
3 & 0,004 & 0,0 & 100,0 & 0,065 \\
\hline
\end{tabular}

Tabela 7. Testes Wilks' Lambda e Qui-quadrado para as três funções discriminantes.

Table 7. Test Wilks' Lambda and Chi-square for the three discriminant functions.

\begin{tabular}{lccc}
\hline Funções & Wilks' Lambda & Qui-quadrado & Sig. \\
\hline 1 a 3 & 0,007 & 78,603 & 0,000 \\
2 a 3 & 0,550 & 9,571 & 0,144 \\
3 & 0,996 & 0,068 & 0,966 \\
\hline
\end{tabular}

\section{Conclusões}

As análises fatorial, agrupamento hierárquico e discriminante contribuíram com o entendimento dos processos que interferem na qualidade das águas subterrâneas de CRAJUBAR no Vale do Cariri Cearense.

A análise fatorial aplicada a variáveis físico-químicas das águas subterrâneas mostrou que três componentes respondem por aproximadamente $85 \%$ da variância total: o primeiro como indicador da dissolução dos minerais presentes na Formação Rio da Batateira (quartzo, feldspatos potássicos e micas) e na Formação Santana da Chapada do Araripe (calcita e gipsita). 0 segundo e o terceiro fatores como indicadores de uma possível mistura entre as águas naturais do aquífero com águas poluídas.

A análise de agrupamento multivariada, aplicada às variáveis do primeiro componente da análise fatorial apresentou dendrogramas com formação de quatro grupos; as variáveis do segundo e terceiro componentes formaram dois grupos, compostos individualmente por amostras com diferentes faixas de concentrações.

0 dendrograma proveniente do agrupamento das variáveis do primeiro fator indicou a mistura entre as águas de recarga na área de estudo e as provenientes da dissolução dos minerais presentes principalmente nas Formações Rio da Batateira e Santana.

0 dendrograma gerado pelo agrupamento das variáveis do segundo fator (Fe total, $\mathrm{P}_{-} \mathrm{PO}_{4}{ }^{3-}$, turbidez e cor) mostrou a forte influência antropogênica na composição dessa água. 
0 dendrograma gerado pelo agrupamento das variáveis do terceiro fator apontou a possível relação dos íons $\mathrm{Cl}^{-}$e $\mathrm{NO}_{3}^{-}$com fontes de poluição de origem orgânica.

As variáveis mais significativas (discriminantes) nos processos responsáveis pela evolução hidroquímica da área foi o $\mathrm{Mg}^{2+}$ e $\mathrm{K}^{+}$, podendo estar relacionados a processos de troca iônica e intemperismo de feldspatos.

Os resultados mostraram que o uso da análise fatorial, associada à análise de agrupamento multivariada e à análise discriminante, é importante no monitoramento e suporte a gestão da qualidade das águas subterrâneas.

Agradecimentos - Os autores agradecem ao CNPq e à FUNCAP, pela bolsa de Desenvolvimento Científico e Tecnológico Regional (DCR) concedida a primeira autora (Processo DCR-002400908.01.00/13).

\section{Referências}

Andrade, E.M., Palácio, H.A., Souza, I.H., Oliveira, L.R.A. \& Guerreiro, M.J. 2008. Land use effects in groundwater composition of an alluvial aquifer (Trussu River, Brazil) by multivariate techniques. Environmental Research, 106(2): 170-177.

Andrade, E.M., Lopes, F.B., Palácio, H.A.Q., Nascimento, D. do \& Alexandre, D.M.B. 2010. Land use and groundwater quality: The case of Baixo Acaraú Irrigated Perimeter, Brazil. Revista Ciência Agronômica, 41(2): 208-215.

Araújo, A.O., Mendonça, L.A.R., Lima, M.G. de S., Feitosa, J.V., Silva, F.J., Ness, R.L.L, Frischkorn, H., Simplício, A.A.F. \& Kerntopf, M.R. 2013. Modificações nas propriedades dos solos de uma área de manejo florestal na Chapada do Araripe. Revista Brasileira Ciência do Solo, 37(3): 754-762.

Arslan, H. 2013. Application of multivariate statistical techniques in the assessment of groundwater quality in seawater intrusion area in Bafra Plain, Turkey. Environmental Monitoring and Assessment, 185(3): 2439-2452.

Brito, L.T.L., Silva, A. de S., Srinivasan, V.S., Galvão, C. de O. \& Gheyi, H.R. 2006. Uso de análise multivariada na classificação das fontes hídricas subterrâneas na bacia hidrográfica do Salitre. Revista Engenharia Agrícola, 26(1): 36-44.

Callegari-Jacques, S.M. 2003. Bioestatística: Princípios e aplicações. Porto Alegre, Artemed, 255p.

Cloutier, V., Lefebvre, R., Therrien, R. \& Savard, M.M. 2008. Multivariate statistical analysis of geochemical data as indicative of the hydrogeochemical evolution of groundwater in a sedimentar rock aquifer system. Journal of Hydrology, 353(3): 294-313.

CPRM. Companhia de Pesquisa de Recursos Minerais. 2007. Mapa geológico da Bacia Sedimentar do Arari- pe. Ceará, escala 1:200.000.

Fernandes, F.B.P., Andrade, E.M. de., Fontenele, S. de B., Meireles, A.C.M. \& Ribeiro, J. 2010. Análise de agrupamento como suporte à gestão qualitativa da água subterrânea no semiárido cearense.Revista Agro@ mbiente On-line, 4(2): 86-95.

Ferreira, D.F. 1996. Análise Multivariada. Lavras, Minas Gerais. 394p.

Franca, R.M. da, Frischkorn, H., Santos, M.R.P., Mendonça, L.A.R. \& Beserra, M.C. 2006. Contaminação de poços tubulares em Juazeiro do Norte-CE. Engenharia sanitária ambiental, 11(1): 92-102.

Gonzalez-Erico, E., Kamprath, E.J., Naderman, G.C. \& Soares, W.V. 1979. Effect of depth of lime incorporation on the growth of corn on an oxisol of central Brazil. Soil Science Society of America Journal, 43(6): 11551158.

Hair Jr., J.F., Anderson, R.E., Tathan, R.L. \& Black, W.C. 1998. Multivariate data analysis. New Jersey, Prentice Hall, 928p.

Hoffmann, R. 1992. Componentes principais e análise fatorial. Piracicaba, Escola Superior de Agricultura Luiz de Queiroz, 25p.

IPECE. Instituto de Pesquisa e Estratégia Econômica do Ceará. 2015. Perfil Básico Municipal. Disponível em: http://www.ipece.ce.gov.br/index.php/perfil-basico-municipal-2014. Acesso em: 06 set. 2015.

Lambrakis, N., Antonakos, A. \& Panagopoulos, G. 2004. The use of multicomponent statistical analysis in hydrogeological environmental research. Water Research, 38(7): 1862-1872.

Landim, P.M.B. 2011. Análise estatística de dados geológicos multivariados. Oficina de textos, São Paulo, $208 \mathrm{p}$.

Logan, J. 1965. Interpretação de análises químicas de água. Recife, $67 \mathrm{p}$.

Lucena, L.R.F. de, Rosa Filho, E.F. da, Bittencourt, A.V.L. \& Montaño, J.X. 2004. A migração de constituintes iônicos no aquífero Barreiras na região sul de Natal-RN, decorrente do quadro estrutural local - uma hipótese de trabalho. Revista Latino-Americana de Hidrogeologia, 4(1): 9-16.

Machado, C.J.F. 2005. Modelagem geoquímica e de fluxos do sistema aquífero subterrâneo na Bacia Sedimentar do Araripe. Fortaleza, 159p. Tese de Doutorado, Programa de Pós-graduação em Física, Universidade Federal do Ceará.

Machado, C.J.F., Santiago, M.M.F., Mendonça, L.A.R., Frishkorn H. \& Mendes Filho, J. 2004. Hidrogeoquímica como indicador de interconexão entre aquíferos na chapada do Araripe utilizando o aplicativo PHREEQC. Revista Águas Subterrâneas, 18(1): 79-87.

Machado, C.J.F., Santiago, M.M.F., Frischkorn, H. \& Mendes Filho, J. 2008. Clustering of groundwaters by Q-mode factor analysis according to their hydrogeochemical origin: A case study of the Cariri Valley (Northern Brazil) wells. Water SA (on-line), 34(5): 651-656.

Manly, B.F.J. 1998. Multivariate statistical methods. London, Chapman \& Hall, 215p.

Mário, P.C. 2014. Análise Discriminante. In: Corrar, L.J., 
Paulo, E. \& Dias Filho, J.M. (Ed.). Análise Multivariada. Fipecafi, São Paulo, p. 232-279.

Palácio, H.A.Q. 2009. Salinidade da qualidade das águas superficiais da bacia do Curu, Ceará. Ciência Rural, 39(9): 2494-2500.

Pearson, R.W., Abruna, F. \& Vicent-Chandler, J.E. 1962. Effect of lime and nitrogen applications on downward movement of calcium and magnesium in two humid tropical soil of Puerto Rico. Soil Science, 93(2): 77-82.

Ponte, F.C. \& Appi, C.J. 1990. Proposta de revisão da coluna litoestratigráfica da bacia do Araripe. In: CONGRESSO BRASILEIRO DE GEOLOGIA, 1990, Natal. Anais... Natal, SBG, p. 211-226.

Salgado, E.V., Andrade, E.M. de, Fontenele, S. de B. \& Meireles, A.C.M. 2011. Similaridade das variáveis hidroquímicas com o uso da análise multivariada, na Bacia do Salgado, Ceará. Revista Caatinga, 24(3): 158-166.

Santos, A.C. 2008. Noções de Hidroquímica. In: Feitosa, F.A.C., Manoel Filho, J., Feitosa, E.C. \& Demetrio, J.G.A. (Ed.). Hidrogeologia: Conceitos e Aplicações. CPRM, Rio de Janeiro, , p. 325-357.

Santos, M.R.P., Santiago, M.F., Mendonça, L.A.R., Frischkorn, H. \& Mendes Filho, J. 2014. Modelagem do transporte de cloreto proveniente de esgoto urbano em um aquífero sedimentar usando MT3D: o caso da bateria de poços de Juazeiro do Norte (CE). Engenharia Sanitária e Ambiental, 19(3): 283-292.

SIAGAS. Sistema de Informações de Águas Subterrâneas. 2016. Banco de dados de poços do Ceará. Disponível em: <http://siagasweb.cprm.gov.br/layout/ pesquisa_complexa.php>. Acesso em: 22 set. 2016.

Silva, C.J.C. 2013. Influência antrópica na composição dos sedimentos da rede de drenagem natural em Juazeiro do Norte - CE. Fortaleza, 110p. Dissertação de Mestrado, Programa de Pós-graduação em Desenvolvimento Regional Sustentável, Universidade Federal do Cariri.

Vega, M., Pardo, R., Barrado, E. \& Debán, L. 1998. Assessement of seasonal and polluting effects on the quality of river water by exploratory data analysis. Water Research, 32(12): 3581-3592.

Wang, Y. \& Luo, T.Z. 2001. Geostatistical and geochemical analysis of surface water leakage into groundwater on a regional scale: a case study in the Liulin Karst system, northwestern China. Journal of hydrology, 246(1): 223-234.

Yidana, S.M., Ophori, D. \& Banoeng-Yakubo, B. 2008. A multivariate statistical analysis of surface water chemistry data. The Ankobra basin, Ghana. Journal of Environmental Management, 86(1): 80-87.

Manuscrito 633

Editores: Katia Kellem Rosa \& Maria do Carmo Lima e Cunha 
